\title{
Hypoglycemic Properties of Oxovanadium (IV) Coordination Compounds with Carboxymethyl-Carrageenan and Carboxymethyl-Chitosan in Alloxan-Induced Diabetic Mice
}

\author{
Hongyu Zhang, ${ }^{1,2}$ Yuetao Yi, ${ }^{1,3}$ Dawei Feng, ${ }^{1}$ Yipeng Wang, ${ }^{1}$ and Song Qin ${ }^{1,3}$ \\ ${ }^{1}$ Yantai Institute of Coastal Zone Research, Chinese Academy of Sciences, Yantai 264003, China \\ ${ }^{2}$ Graduate School of Chinese Academy of Sciences, Beijing 100049, China \\ ${ }^{3}$ Biological Resources Laboratory, Yantai Institute of Coastal Zone Research, Chinese Academy of Sciences, Yantai, 264003, China
}

Correspondence should be addressed to Yuetao Yi, ytyi@yic.ac.cn and Song Qin, sqin@yic.ac.cn

Received 12 January 2011; Accepted 1 June 2011

Copyright ( 2011 Hongyu Zhang et al. This is an open access article distributed under the Creative Commons Attribution License, which permits unrestricted use, distribution, and reproduction in any medium, provided the original work is properly cited.

\begin{abstract}
In order to avoid low absorption, incorporation, and undesirable side effects of inorganic oxovanadium compounds, the antidiabetic activities of organic oxovanadium (IV) compounds in alloxan-induced diabetic mice were investigated. Vanadyl carboxymethyl carrageenan (VOCCA) and vanadyl carboxymethyl chitosan (VOCCH) were synthesized and administrated through intragastric administration in different doses for 20 days in alloxan-induced diabetic mice. Glibenclamide was administrated as the positive control. Our results showed that low-dose group, middle-dose group, and high-dose group of VOCCA and VOCCH could significantly reduce the levels of blood glucose $(P<0.05)$ compared with untreated group, but not in normal mice. Besides, high-dose groups of VOCCA and VOCCH exhibited more significant hypoglycemic activities $(P<0.01)$. After treated with $\mathrm{VOCCH}$, the oral glucose tolerance of high-dose group of VOCCH was improved compared with model control group $(P<0.05)$.
\end{abstract}

\section{Introduction}

Diabetes mellitus (DM), which results from insulin deficiency or insulin resistance, is a serious chronic metabolic disease [1]. The DM includes insulin-dependent type $1 \mathrm{DM}$ and non-insulin-dependent type $2 \mathrm{DM}$. Until now, type 1 DM can only be controlled by subcutaneous injections of insulin, which causes many problems to the patients. In order to treat type $2 \mathrm{DM}$, some drugs have also been synthesized [2], for example, sulfonylureas, sulfonamides, biguanides, thiozolidinediones, and so on. Orally active therapeutic agents instead of painful insulin injections for type $1 \mathrm{DM}$ and synthetic drugs without side effects for type $2 \mathrm{DM}$ have become an urgent and important requirement.

Vanadium is not only an important trace element for organisms, but also the necessary element for human body [3]. It has been demonstrated that many vanadium compounds possess therapeutic effects as insulin mimetics $[4,5]$. Heyliger et al. first reported the insulin mimetic activity of oral vanadate in vivo in 1985 [6]. Since then, extensive studies have been carried out to explore vanadium chemistry, including the synthesis of novel complexes and their antidiabetic activities both in vitro and in vivo [7-16]. Furthermore, many clinical trials of vanadium compounds have also been reported [17-20], in which vanadium salts such as $\mathrm{VOSO}_{4}$ and $\mathrm{NaVO}_{3}$ were administered to diabetic patients. In order to enhance both lipophilicity and bioavailability of vanadium compound, overcome the disadvantage of side effects, increase the half-life of the compound, decrease systemic drug toxicity, improve treatment absorption rates, and provide protection for pharmaceuticals against biochemical degradation, two types of less toxic vanadyl ( +4 oxidation state of vanadium) complexes with different coordination structures were synthesized and examined.

In addition, the polysaccharide polymer is biodegradable and biocompatible and would be effective in enhancing drug bioavailability through the mechanism of delaying release. In order to investigate the impact of different organic ligands on vanadyl complexes, vanadyl carboxymethyl k-carrageenin and vanadyl carboxymethyl chitosan were synthesized. The 
present study was performed to investigate the antidiabetic properties of these two new vanadyl complexes in alloxaninduced diabetic mice.

\section{Materials and Methods}

2.1. Materials and Equipments. K-carrageenin and chitosan with a deacetylation degree of $95.3 \%$ were purchased from Qingdao Baicheng Biochemical Corp (China), their viscosity-average molecular weights were $3.77 \times 10^{5}$ and $2.0 \times 10^{5}$, respectively. Isopropanol, glucose, alloxan, and vanadyl sulfate hydrate $\left(\mathrm{VOSO}_{4} \cdot x \mathrm{H}_{2} \mathrm{O}, x=3\right.$ to 5 ) were purchased from the Sigma-Aldrich Chemical Co. Glibenclamide was purchased from Pacific pharmaceutical technology group. Ethanol, sodium hydroxide, and other reagents were purchased from Sinopharm Co. Kunming mice were provided by experimental animal center, Kunming. The IR spectra were measured on a JASCO-4100FT-IR spectrometer with $\mathrm{KBr}$ disks. The content of vanadium is measured on 7AS-986 (G) Atomic Absorption Spectrometer. Chemicals and solvents were reagent grade.

2.2. Synthesis of VOCCA and VOCCH. K-carrageenin (chitosan) (50 g) was added into $750 \mathrm{~mL}$ isopropanol and stirred for $30 \mathrm{~min} .40 \mathrm{~mL}$ sodium hydroxide solution (mass fraction is $50 \%$ ) was slowly dropped into the mixture $(25 \mathrm{~min}$ ) and stirred for $3 \mathrm{~h}$. Then $60 \mathrm{~g}$ monochloroacetic acid was added into the mixture for 5 times in $30 \mathrm{~min}$, and the system temperature was kept at $60^{\circ} \mathrm{C}$ for $4 \mathrm{~h}$. After incubating for $4 \mathrm{~h}$, the temperature was lowered to $25^{\circ} \mathrm{C}$ and the $\mathrm{pH}$ was adjusted to 7.0. The mixture was then concentrated with ethanol three times in volume of the mother liquid. After filtration, washing, drying, and smashing, the carboxymethyl carrageenin and carboxymethyl chitosan were obtained.

Ashing method [21] was applied to calculate the SD of carboxymethyl groups of carboxymethyl carrageenin and carboxymethyl chitosan. Carboxymethyl carrageenin and carboxymethyl chitosan were vacuum dried at $60^{\circ} \mathrm{C}$ to constant mass; carboxymethyl carrageenin and carboxymethyl chitosan were heated and scorched at $700^{\circ} \mathrm{C}$ for $15-20 \mathrm{~min}$. The residues were $\mathrm{Na}_{2} \mathrm{O}$, leached with $50 \mathrm{~mL} \mathrm{HCl}$ solution $(0.1 \mathrm{moI} / \mathrm{L})$, heated, and followed by residual titration with $0.1 \mathrm{~mol} / \mathrm{L}$ standard $\mathrm{NaOH}$. The SD of carboxymethyl groups of carboxymethyl carrageenin and carboxymethyl chitosan were calculated as the formula discussed by Wang and Ye.

Vanadyl carboxymethyl carrageenin (chitosan) (the SD of carboxymethyl carrageenin and carboxymethyl chitosan were $47.3 \%$ and $84.9 \%$, resp.) was prepared by mixing various amounts of $\mathrm{VOSO}_{4}$ with carboxymethyl carrageenin (the mass ratio of $\mathrm{V}$ to carboxymethyl carrageenin (chitosan) was $1 \%$ ) solutions under magnetic stirring for $24 \mathrm{~h}$ at room temperature. Ethanol four times in volume of the mother liquid was added to the solution to complete precipitation of vanadyl carboxymethyl carrageenin (chitosan) complex. The resulting precipitate was washed with ethanol and dried under a vacuum condition at room temperature, and white solid vanadyl carboxymethyl carrageenin and carboxymethyl chitosan were obtained. VOCCA and VOCCH were dissolved in tap water to the concentration of $5 \%(\mathrm{w} / \mathrm{v})$ every day and kept at $4^{\circ} \mathrm{C}$.

2.3. Vanadium Content Determination. 7AS-986 (G) Atomic Absorption Spectrometry was applied to determine the content of vanadium of the complex according to the standard method of the instruction.

2.4. Maximal Tolerant Dose (MTD) Determination of VOCCA. The result of preliminary acute toxicity test showed no death of mouse. Afterwards, the Maximal Tolerant Dose (MTD) test was carried out. Twenty normal mice weighing $20 \pm 2 \mathrm{~g}$ were fasted for $24 \mathrm{~h}$, then VOCCA $(5 \%, 0.8 \mathrm{~mL})$ was administered intragastrically three times a day for two weeks. After two weeks, the maximum tolerated dose was calculated according to the formula:

$$
\text { MTD }=\frac{\text { the dose of intragastric administration } \times 3}{\text { body weight of rat }} .
$$

2.5. Construction of Diabetic Mouse Model. Male mice weighing 20-24 g were used for animal model construction. Mice were fasted for $24 \mathrm{~h}$ and then intraperitoneally injected alloxan $(160 \mathrm{mg} / \mathrm{kg})$. Five days after alloxan injection, the mice were fasted for $6 \mathrm{~h}$ and blood samples were obtained from tail vein of the mice. The blood glucose levels were measured by the glucose oxidase method. The alloxaninjected mice with the blood glucose level between 10 and $20 \mathrm{mmol} / \mathrm{L}$ were considered as diabetic mice.

2.6. Glucose-Lowering Test. Normal mice and diabetic mice were randomly divided into 6 groups (10 mice per group). Normal control group: normal mice; model control group: diabetic mice treated with tap water; glibenclamide control group: diabetic mice treated with $0.2 \mathrm{~g} / \mathrm{kg}$ glibenclamide; low-dose group: diabetic mice treated with $0.3125 \mathrm{~g} / \mathrm{kg}$ VOCCH and $0.6250 \mathrm{~g} / \mathrm{kg}$ VOCCA; middle-dose group: diabetic mice treated with $0.6250 \mathrm{~g} / \mathrm{kg} \mathrm{VOCCH}$ and $1.250 \mathrm{~g} / \mathrm{kg}$ VOCCA; high-dose group: diabetic mice treated with $1.2500 \mathrm{~g} / \mathrm{kg} \mathrm{VOCCH}$ and $2.500 \mathrm{~g} / \mathrm{kg}$ VOCCA. The samples above were administered intragastrically for 20 days.

2.7. Oral Glucose Tolerance Test (OGTT) of VOCCH. After the VOCCH was administered intragastrically in both normal and alloxan-induced diabetic mice for 20 days, oral glucose tolerance test was executed. Glucose loaded with the single dose of $2.5 \mathrm{~g} / \mathrm{kg}$ was intragastrically administered to mice fasted for $6 \mathrm{~h}$, and the blood glucose level was checked at $0,0.5,2 \mathrm{~h}$.

2.8. Blood Sample Collection. The blood samples were obtained from tail vein of mice. Firstly, the tail of mouse was put into hot water $\left(50^{\circ} \mathrm{C}\right)$ for several minutes and cleaned, then the tail tip was cut for 1-2 mm long and blood sample was obtained.

2.9. Statistical Analysis. All data were expressed as the mean \pm SD. Statistical analysis was performed by one-way analysis 


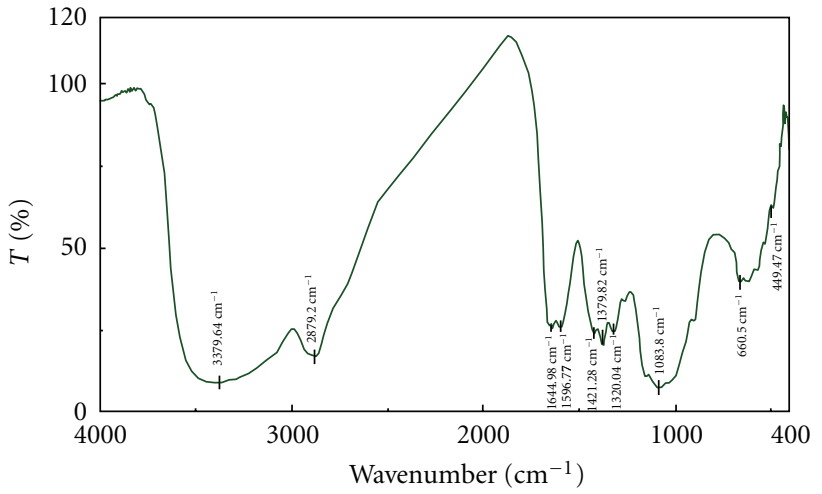

FIGURE 1: FT-IR spectra of chitosan.

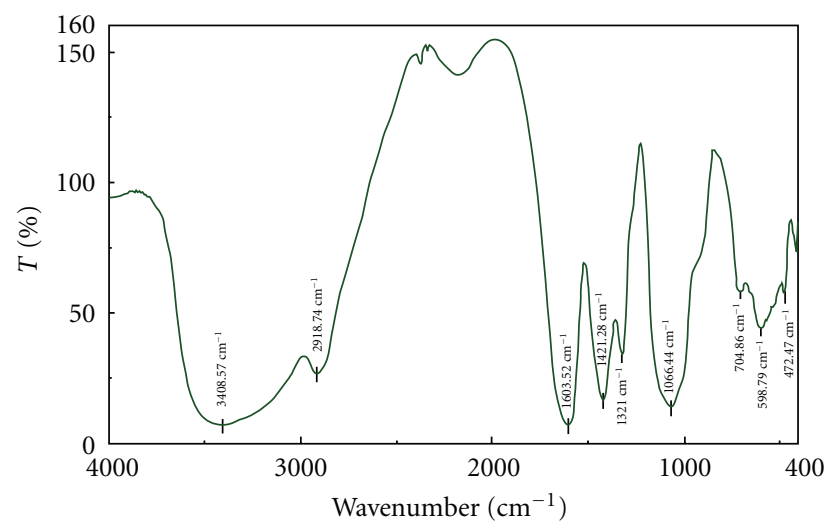

FIGURE 2: FT-IR spectra of carboxymethyl chitosan.

of variance (ANOVA) followed by the least significant difference (LSD) test for the multiple comparisons among the groups. Values for $P<0.05$ were considered statistically significant.

\section{Result}

3.1. Character of VOCCA and VOCCH. Figures 1, 2, and 3 are infrared spectra of chitosan, carboxymethyl chitosan, and vanadyl carboxymethyl chitosan. Infrared spectrum (Figure 2) showed that $\mathrm{C}-\mathrm{OH}$ stretching vibration absorption peak of carboxymethyl chitosan was located at $1066.44 \mathrm{~cm}^{-1}, \mathrm{~N}-\mathrm{H}$ and $\mathrm{O}-\mathrm{H}$ at $3408.57 \mathrm{~cm}^{-1},-\mathrm{OH}$ antisymmetrical stretching vibration absorption peak (COO) was located at $1603.52 \mathrm{~cm}^{-1}$, and its symmetrical stretching vibration (COO) absorption peak was at $1421.28 \mathrm{~cm}^{-1}$.

Infrared spectrum of VOCCH (Figure 3 ) showed that C$\mathrm{OH}$ absorption peak was displaced to $1070.30 \mathrm{~cm}^{-1}, \mathrm{~N}-\mathrm{H}$ and $\mathrm{O}-\mathrm{H}$ absorption peaks were displaced to $3371.92 \mathrm{~cm}^{-1}$, $\mathrm{OH}$ antisymmetrical stretching vibration absorption peak and its symmetrical stretching vibration (COO) absorption peak were displaced to $1599.66 \mathrm{~cm}^{-1}$ and $1416.46 \mathrm{~cm}^{-1}$. This indicated that carboxyl, amino-group, and hydroxyl participated in the interaction of carboxymethyl chitosan and $\mathrm{VO}^{2+}$. The content of $\mathrm{V}$ in $\mathrm{VOCCH}$ was $0.36 \%$.

Figures 4, 5, and 6 are the IR spectra of carrageenan, carboxymethyl carrageenan, and vanadyl carboxymethyl

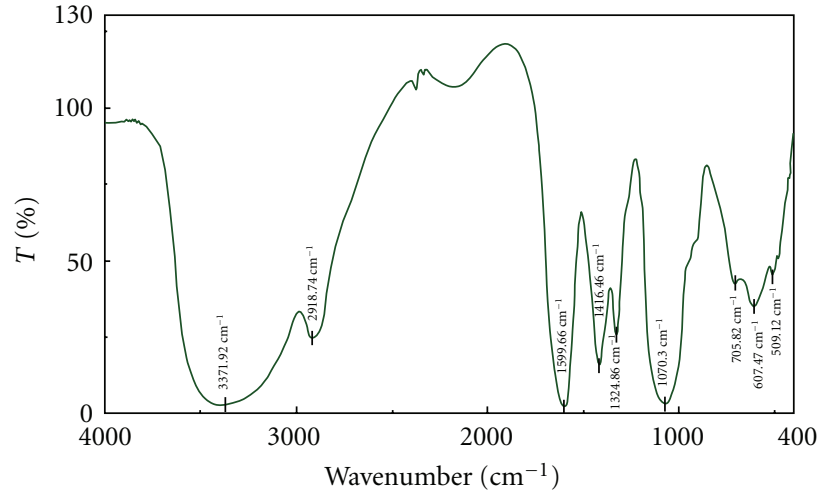

FIGURE 3: FT-IR spectra of vanadyl carboxymethyl chitosan.

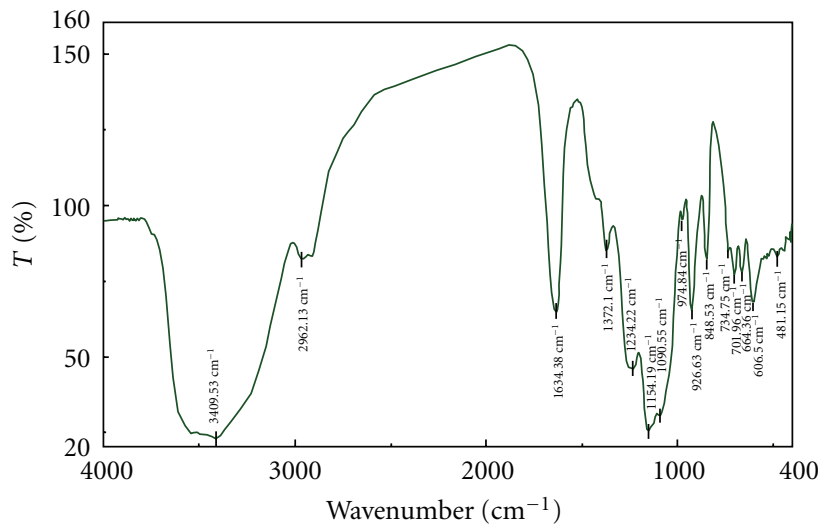

Figure 4: FT-IR spectra of carrageenan.

carrageenan. Compared to the carrageenan, carboxymethyl carrageenan showed characteristic peak $1610 \mathrm{~cm}^{-1}$ of $\mathrm{C}=\mathrm{O}$ group. Further, the peak of $\mathrm{C}=\mathrm{O}$ in carboxymethyl carrageenan at $1610 \mathrm{~cm}^{-1}$ shift to $1604 \mathrm{~cm}^{-1}$ of vanadyl carboxymethyl carrageenan, also the shifts of absorption peaks of $\mathrm{S}=\mathrm{O}$ and $\mathrm{OH}$ were observed (Figure 6). These results clearly indicated the incorporation of carboxymethyl group and $\mathrm{VO}^{2+}$ into carrageenan and carboxymethyl carrageenan, respectively. The content of $\mathrm{V}$ of VOCCA measurement on Atomic Absorption Spectrometry was 0.18\%.

3.2. MTD of VOCCA. In the test of maximal tolerant dose, there were no convulsions, vomiting, or other negative symptoms.

$$
\mathrm{MTD}=0.8 \mathrm{~mL} \times 5 \mathrm{~g} / \mathrm{mL} \times \frac{3}{20} \mathrm{~g}=6.0 \mathrm{~g} / \mathrm{Kg} .
$$

3.3. Glucose-Lowering Studies and OGTT. In Figures 7 and 8 , the body weights of each group before and after treatment with VOCCA and VOCCH are shown. In this study, the body weights of diabetic mice were lowered compared with those of normal control mice throughout the experimental period of 20 days. At the end of the experiment, the body weights of vanadium-treated groups exhibited no significant deviation with model control group and glibenclamide control group. 


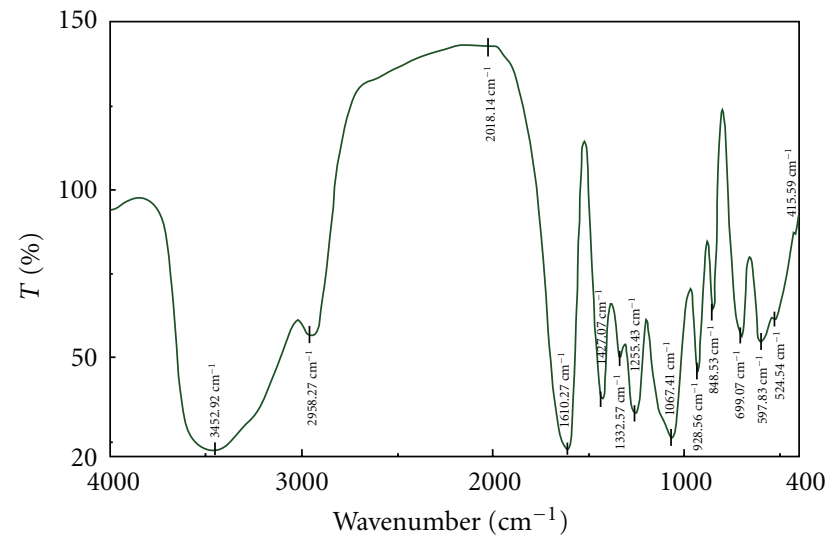

FIGURE 5: FT-IR spectra of carboxymethyl carrageenan.

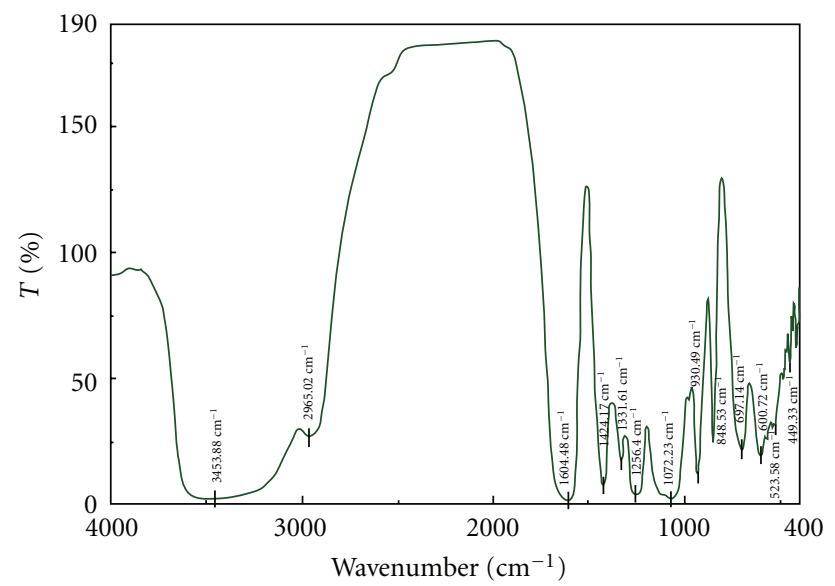

FIGURE 6: FT-IR spectra of vanadyl carboxymethyl carrageenan.

The body weight profile indicated that there was no negative impact on body weight of the mice after treated with both VOCCA and VOCCH. These complexes showed comparable results with other vanadyl coordination compounds [22].

The changes of blood glucose levels are shown in Tables 1 and 2. The initial blood glucose levels of the diabetic mice were similar. Low-dose group, middle-dose group, and high-dose group of VOCCA could statistically significantly reduce the levels of blood glucose $(P<0.05)$ compared with model control group, and high-dose group of VOCCA had more significant hypoglycemic activity $(P<0.01)$ (Table 1). There was no obvious difference among low-dose group, middle-dose group, and high-dose group compared with glibenclamide control group $(P>0.05)$. Low-dose group, middle-dose group, and high-dose group of VOCCH could statistically significantly reduce the levels of blood glucose $(P<0.05)$ compared to model control group. However, high-dose group showed more apparent effect than glibenclamide control group $(P<0.01)$ (Table 2). Furthermore, the oral glucose tolerance was improved in diabetic animals after treated with VOCCH $(P<0.05)$ (Figure 9). Meanwhile, low-dose group, middle-dose group, and high-dose group of VOCCA and VOCCH showed no

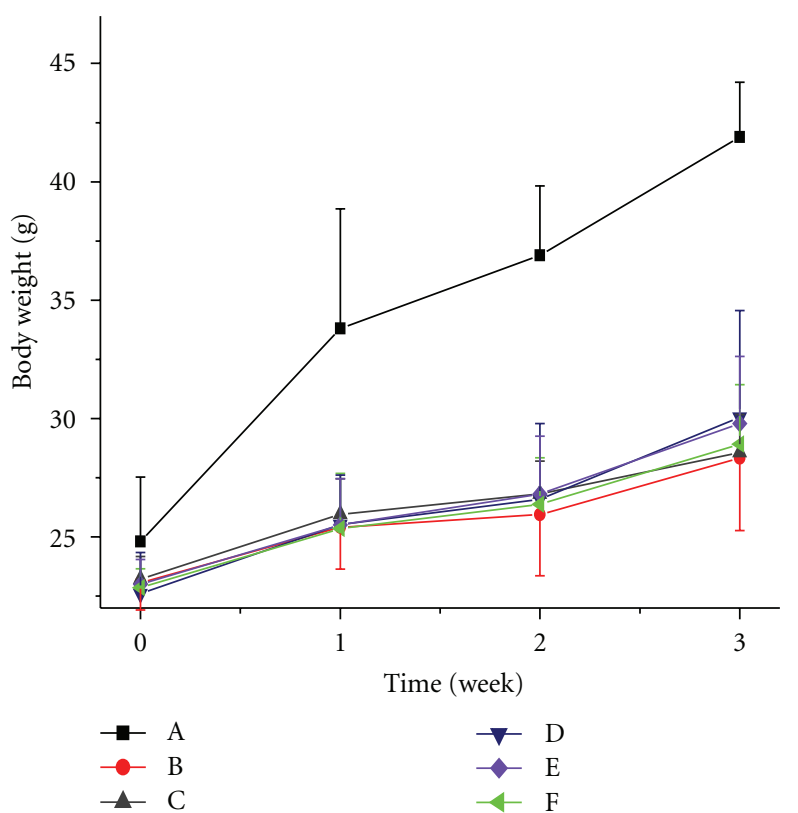

FIGURE 7: Impacts of intragastric VOCCA administration on body weight in both normal and alloxan-diabetic mice; (A): normal control group, (B): model control group, (C): glibenclamide control group, (D): low dose group, (E): middle dose group, (F): high dose group.

TABLE 1: Impacts of intragastric VOCCA on blood glucose levels in both normal and alloxan-diabetic mice.

\begin{tabular}{lccc}
\hline Group & $\begin{array}{c}\text { Dose } \\
\left(\mathrm{g} \cdot \mathrm{Kg}^{-1}\right)\end{array}$ & 0 week & 3 week \\
\hline $\begin{array}{l}\text { Normal control group } \\
\text { Model control group }\end{array}$ & 0 & $5.7 \pm 0.6$ & $6.0 \pm 0.16$ \\
$\begin{array}{l}\text { Glibenclamide } \\
\text { control group }\end{array}$ & 0.2000 & $17.8 \pm 4.6$ & $32.2 \pm 3.3$ \\
Low-dose group & 0.6250 & $18.0 \pm 4.3$ & $26.7 \pm 2.6$ \\
Middle-dose group & 1.2500 & $17.8 \pm 4.4$ & $28.1 \pm 5.0^{\text {ad }}$ \\
High-dose group & 2.500 & $17.6 \pm 4.3$ & $25.9 \pm 4.7^{\text {ac }}$ \\
\hline
\end{tabular}

${ }^{\mathrm{a}} P<0.01,{ }^{\mathrm{b}} P<0.05$, versus normal control group; ${ }^{\mathrm{c}} P<0.01,{ }^{\mathrm{d}} P<0.05$, versus model control group.

negative influence on blood glucose levels of normal mice (Tables 1 and 2).

Among low-dose group, middle-dose group and highdose group of VOCCA and VOCCH at the same concentration of vanadium, the blood glucose levels of $\mathrm{VOCCH}$ groups reduced from 29.8 (model control group) to 24.2, 22.4, 17.1, respectively, while VOCCA groups reduced from 32.2 (model control group) to $28.9,28.1$, and 25.9, respectively, which indicated that VOCCH would be better candidate as insulin enhancer than VOCCA.

As shown in Figure 9, the blood glucose concentrations of mice increased greatly after loading with $\mathrm{D}$-glucose and then reduced smoothly. In the OGTT test, the blood glucose concentrations of normal mice remained less than $8 \mathrm{mM}$, while the model control group was consistently higher than that of the vanadium-treated groups. The blood glucose 


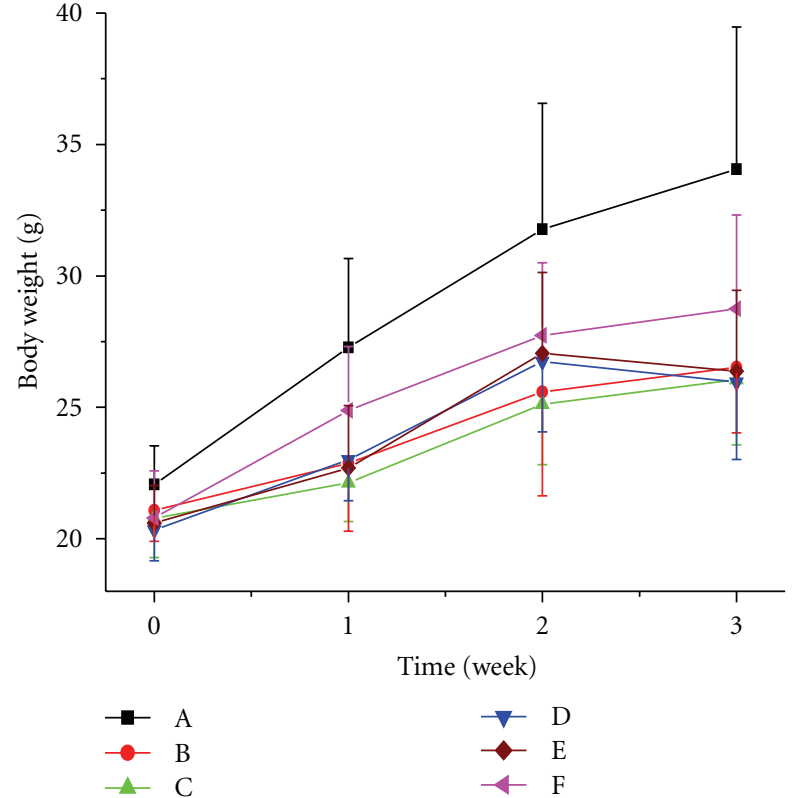

FIGURE 8: Impacts of intragastric VOCCH administration on body weight in both normal and alloxan-diabetic mice; (A): normal control group, (B): model control group, (C): glibenclamide control group, (D): low-dose group, (E): middle-dose group, (F): high-dose group.

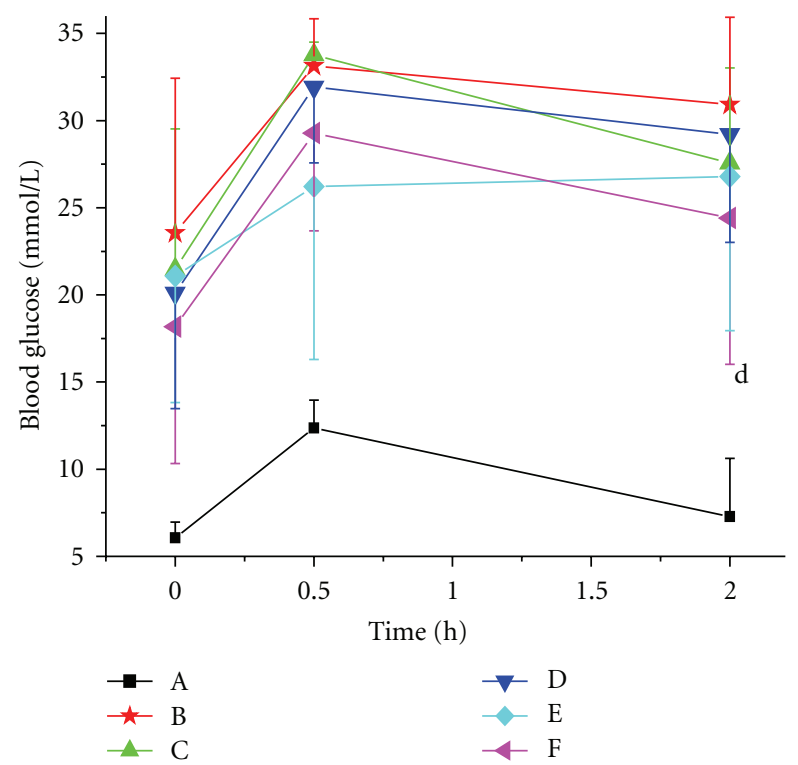

FIGURE 9: Impacts of VOCCH on glucose tolerance in normal mice and alloxan-diabetic mice. (A): normal control group, (B): model control group, (C): glibenclamide control group, (D): low dose group, (E): middle dose group, $(\mathrm{F})$ : high dose group. $d^{P}<0.05$, versus model control group.

levels of diabetic mice remained above the basal levels at the end of the test. However, the blood glucose concentrations of vanadium treated groups were significantly lower than model control groups. Furthermore, the results of the OGTT indicated that impaired glucose tolerance was improved after treatment with VOCCH.
TABLE 2: Impacts of intragastric VOCCH on blood glucose levels in both normal and alloxan-diabetic mice.

\begin{tabular}{|c|c|c|c|}
\hline Group & $\begin{array}{c}\text { Dose } \\
\left(\mathrm{g} \cdot \mathrm{Kg}^{-1}\right)\end{array}$ & 0 week & 3 week \\
\hline Normal control group & 0 & $5.7 \pm 0.6$ & $5.1 \pm 0.5$ \\
\hline Model control group & 0 & $17.0 \pm 4.7$ & $29.8 \pm 5.4$ \\
\hline $\begin{array}{l}\text { Glibenclamide } \\
\text { control group }\end{array}$ & 0.200 & $17.1 \pm 4.5$ & $21.4 \pm 4.5$ \\
\hline Low-dose group & 0.3125 & $17.6 \pm 4.7$ & $24.2 \pm 3.4^{\mathrm{ad}}$ \\
\hline Middle-dose group & 0.6250 & $17.5 \pm 4.4$ & $22.4 \pm 5.6^{\mathrm{ac}}$ \\
\hline High-dose group & 1.2500 & $17.2 \pm 4.3$ & $17.1 \pm 6.9^{\text {acf }}$ \\
\hline
\end{tabular}

\section{Discussion}

Insulin-mimetic properties of vanadium salts and vanadium compounds have been widely reported in both type 1 and type 2 diabetic animal models [23-25]. Inorganic vanadium compounds have already been known to be effective in treatment of diabetic hyperglycemia, but the side effects, such as vomiting, diarrhea, hepatic, and renal toxicity limit their application $[26,27]$. Organic vanadium coordination compounds have been proved with better absorption efficiency in gastrointestinal tract [28]. In this study, high doses of VOCCH and VOCCA exhibited antidiabetic activity at significantly lower intake levels of elemental vanadium compared to glibenclamide. Vomiting and diarrhea, the major side effects of vanadium compounds, were not observed. For example, BMOV and similar compounds like bis (ethylmaltolato) oxovanadium (IV) (BEOV) have already been in clinical trials [29]. However, the toxicity, lower bioavailability and nonlinear pharmacokinetics of these compounds compromise their pharmacological success [30]. These results indicated that the corporation of essential trace element vanadium and polysaccharide could enhance their biological activity, intercoordination, and bioavailability. The insulinenhancing properties of organic vanadium complexes have previously been compared with those of inorganic vanadium salts $[31,32]$. It was reported that vanadium-enriched Cordyceps sinensis was beneficial for contemporary treatment of depression and diabetes through the coeffect [33]. VOCCA and $\mathrm{VOCCH}$ also may be potential strategies for lowering the blood sugar level through the coeffect of vanadium and carboxymethyl-carrageenan and carboxymethyl-chitosan. In the present study, VOCCH, VOCCA, and $\mathrm{VOSO}_{4}$ showed similar hypoglycemic functions. However, the vanadium intake amount in the form of VOCCH and VOCCA was significantly lower than that of $\mathrm{VOSO}_{4}$ [22]. These results indicated that the anti-diabetic abilities of $\mathrm{VOCCH}$ and VOCCA were more effective than $\mathrm{VOSO}_{4}$.

\section{Conclusion}

A beneficial role of enhancing anti-diabetic actions of $\mathrm{VOCCH}$ and VOCCA was found in this study. VOCCH 


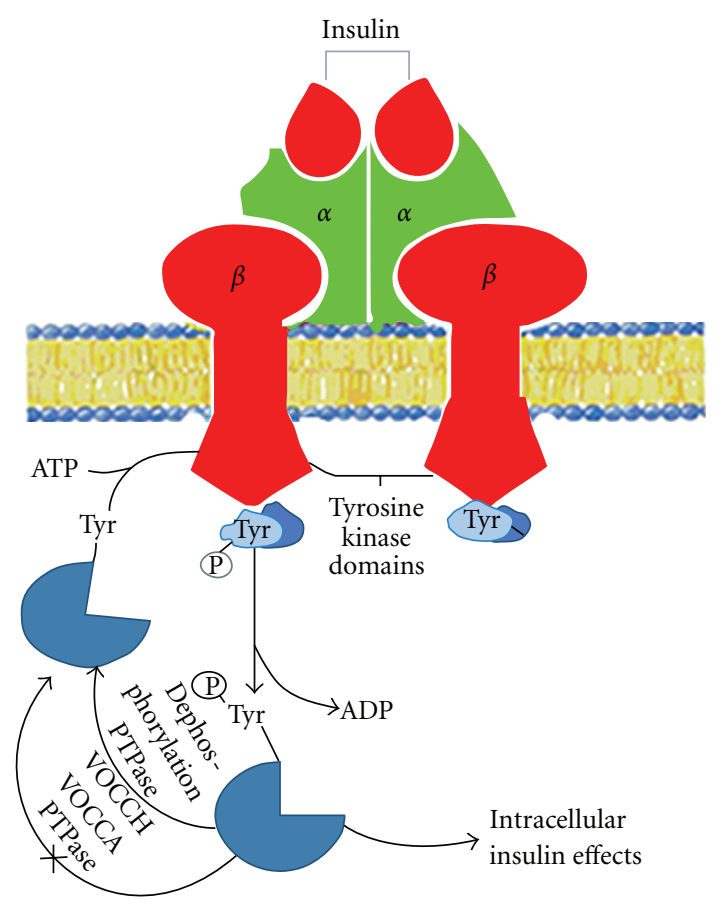

FIGURE 10: Schematic presentation of insulin signal transduction and possible action mechanisms of VOCCH and VOCCA.

and VOCCA would be good candidates of insulin enhancers to effectively activate glucose metabolism in vivo and regulate glucose metabolism by influencing insulin levels. The ligands of carboxymethyl carrageenin and carboxymethyl chitosan allowed vanadium to supply at the minimal doses, prolonged the duration of drug activity, and reduced the toxicity of vanadium. This implied that carboxymethyl carrageenin and carboxymethyl chitosan would be promising biocompatible and biodegradable vehicles for the delivery of $\mathrm{VO}^{2+}$ ions.

Insulin receptor which is a kind of transmembrane glycoprotein complex molecules consists of two alpha subunits ( $135 \mathrm{kd}$ ) and two beta subunits ( $95 \mathrm{kd})$; they linked by three disulfide bonds. Alpha subunits are outside of cell; beta subunits are embedded in membranes. The combination of insulin and alpha subunits caused phosphorylation of multiple tyrosine residues of beta subunits, which activated protein tyrosine kinase (PTK) and triggered a series of cascade amplification reaction of phosphorylation and dephosphorylation to adjust the metabolism. PTPase (protein tyrosine phosphatase) is the main negative regulatory factor in insulin signaling pathways; it caused dephosphorylation of insulin receptor and its substrate and weakened insulin signals.

Possible mechanisms for hypoglycemic properties of VOCCA and VOCCH are as follows: VOCCA and VOCCH could inhibit the dephosphorylation activity of PTPase, so dephosphorylation of tyrosine kinase and downstream signal substrate will be inhibited. In this way, the action time of insulin signal was prolonged, so VOCCA and VOCCH could lower the blood sugar level (Figure 10).

\section{Acknowledgments}

This work was supported by the Knowledge Innovation Program of the Chinese Academy of Sciences (KZCX2-YW-225), the Science \& Technology Development Plan of Shandong Province (2010GSF10208), and the CAS/SAFEA International Partnership Program for Creative Research Teams.

\section{References}

[1] H. Sakurai, "A new concept: the use of vanadium complexes in the treatment of diabetes mellitus," Chemical Record, vol. 2, no. 4, pp. 237-248, 2002.

[2] H. Sakurai and H. Yasui, "Structure-activity relationship of insulinomimetic vanadyl-picolinate complexes in ciew of their clinical use," Journal of Trace Elements in Experimental Medicine, vol. 16, no. 4, pp. 269-280, 2003.

[3] B. Mukherjee, B. Patra, S. Mahapatra, P. Banerjee, A. Tiwari, and M. Chatterjee, "Vanadium-an element of a typical biological significance," Toxicology Letters, vol. 150, no. 2, pp. 135-143, 2004.

[4] Y. Shechter and S. J. D. Karlish, "Insulin-like stimulation of glucose oxidation in rat adipocytes by vanadyl (IV) ions," Nature, vol. 284, no. 5756, pp. 556-558, 1980.

[5] J. Meyerovitch, Z. Farfel, J. Sack, and Y. J. Shechter, "Oral administration of vanadate normalizes blood glucose levels in streptozotocin-treated rats: characterization and mode of action," The Journal of Biological Chemistry, vol. 262, no. 14, pp. 6658-6662, 1987.

[6] C. E. Heyliger, A. G. Tahiliani, and J. H. McNeill, "Effect of vanadate on elevated blood glucose and depressed cardiac performance of diabetic rats," Science, vol. 227, no. 4693, pp. 1474-1477, 1985.

[7] S. M. Brichard and J. C. Henquin, "The role of vanadium in the management of diabetes," Trends in Pharmacological Sciences, vol. 16, no. 8, pp. 265-270, 1995.

[8] N. Sekar, J. Li, and Y. Shechter, "Vanadium salts as insulin substitutes: mechanisms of action, a scientific and therapeutic tool in diabetes mellitus research," Critical Reviews in Biochemistry and Molecular Biology, vol. 31, no. 5, pp. 339-359, 1996.

[9] V. Badmaev, S. Prakash, M. Majeed, and J. Altern, "Vanadium: a review of its potential role in the fight against diabetes," Journal of Alternative and Complementary Medicine, vol. 5, no. 3, pp. 273-291, 1999.

[10] S. M. Brichard, C. J. Bailey, and J. C. Henquin, "Marked improvement of glucose homeostasis in diabetic ob/ob mice given oral vanadate," Diabetes, vol. 39, no. 11, pp. 1326-1332, 1990.

[11] K. H. Thompson and C. Orvig, "Design of vanadium compounds as insulin enhancing agents," Journal of the Chemical Society, Dalton Transactions, no. 17, pp. 2885-2892, 2000.

[12] H. Sakurai, Y. Kojima, Y. Yoshikawa, K. Kawabe, and H. Yasui, "Antidiabetic vanadium(IV) and zinc(II) complexes," Coordination Chemistry Reviews, vol. 226, no. 1-2, pp. 187198, 2002.

[13] S. Karmaker, T. K. Saha, Y. Yoshikawa, H. Yasui, and H. Sakurai, "A novel drug delivery system for type 1 diabetes: insulinmimetic vanadyl-poly ( $\gamma$-glutamic acid) complex," Journal of Inorganic Biochemistry, vol. 100, no. 9, pp. 1535-1546, 2006.

[14] S. Tas, E. Sarandol, S. Z. Ayvalik, Z. Serdar, and M. Dirican, "Vanadyl sulfate, taurine, and combined vanadyl sulfate and taurine treatments in diabetic rats: effects on the oxidative and 
antioxidative systems," Archives of Medical Research, vol. 38, no. 3, pp. 276-283, 2007.

[15] R. Shukla and R. R. Bhonde, "Adipogenic action of vanadium: a new dimension in treating diabetes," BioMetals, vol. 21, no. 2, pp. 205-210, 2008.

[16] J. J. Smee, J. A. Epps, K. Ooms et al., "Chloro-substituted dipicolinate vanadium complexes: synthesis, solution, solidstate, and insulin-enhancing properties," Journal of Inorganic Biochemistry, vol. 103, no. 4, pp. 575-584, 2009.

[17] A. B. Goldfine, D. C. Simonson, F. Folli, M. E. Patti, and C. R. Kahn, "Metabolic effects of sodium metavanadate in humans with insulin-dependent and noninsulin-dependent diabetes mellitus in vivo and in vitro studies," Journal of Clinical Endocrinology and Metabolism, vol. 80, no. 11, pp. 3311-3320, 1995.

[18] N. Cohen, M. Halberstam, P. Shlimovich et al., "Oral vanadyl sulfate improves hepatic and peripheral insulin sensitivity in patients with non-insulin-dependent diabetes mellitus," Journal of Clinical Investigation, vol. 95, no. 6, pp. 2501-2509, 1995.

[19] M. Halberstam, N. Cohen, P. Shlimovich, L. Rossetti, and H. Shamoon, "Oral vanadyl sulfate improves insulin sensitivity in NIDDM but not in obese nondiabetic subjects," Diabetes, vol. 45, no. 5, pp. 659-666, 1996.

[20] K. Cusi, S. Cukier, R. A. DeFronzo, M. Torres, F. M. Puchulu, and J. C. Redondo, "Vanadyl sulfate improves hepatic and muscle insulin sensitivity in type 2 diabetes," Journal of Clinical Endocrinology and Metabolism, vol. 86, no. 3, pp. 1410-1417, 2001.

[21] Z. M. Wang and X. Y. Ye, "Ashing method to determine the degree of carboxymethyl subsititution degrees of carboxymethyl chitosan," Fenxihuaxue, vol. 22, pp. 1121-1124, 1994.

[22] M. Li, J. J. Smee, W. J. Ding, and D. C. Crans, "Antidiabetic effects of sodium 4-amino-2,6-dipicolinatodioxovanadium (V) dihydrate in streptozotocin-induced diabetic rats," Journal of Inorganic Biochemistry, vol. 103, no. 4, pp. 585-589, 2009.

[23] S. Mohammad, A. Taha, R. N. K. Bamezai, and N. Z. Baquer, "Modulation of glucose transporter (GLUT4) by vanadate and Trigonella in alloxan-diabetic rats," Life Sciences, vol. 78, no. 8, pp. 820-824, 2006.

[24] W. J. Ding, T. Hasegawa, H. Hosaka, D. Peng, K. Takahashi, and Y. Seko, "Effect of long-term treatment with vanadate in drinking water on KK mice with genetic noninsulin-dependent diabetes mellitus," Biological Trace Element Research, vol. 80, no. 2, pp. 159-174, 2001.

[25] L. H. Gao, W. P. Liu, B. L. Wang et al., "Effects of bis $(\alpha$-furancarboxylato)oxovanadium(IV) on non-diabetic and streptozotocin-diabetic rats," Clinica Chimica Acta, vol. 368, no. 1-2, pp. 173-178, 2006.

[26] P. Leopardi, P. Villani, E. Cordelli, E. Siniscalchi, E. Veschetti, and R. Crebelli, "Assessment of the in vivo genotoxicity of vanadate: analysis of micronuclei and DNA damage induced in mice by oral exposure," Toxicology Letters, vol. 158, no. 1, pp. 39-49, 2005.

[27] G. B. Garcia, M. E. Biancardi, and A. D. Quiroga, "Vanadium (V)-induced neurotoxicity in the rat central nervous system: a histo-immunohistochemical study," Drug and Chemical Toxicology, vol. 28, no. 3, pp. 329-344, 2005.

[28] A. K. Srivastava, "Anti-diabetic and toxic effects of vanadium compounds," Molecular and Cellular Biochemistry, vol. 206, no. 1-2, pp. 177-182, 2000.
[29] K. H. Thompson, J. Lichter, C. LeBel, M. C. Scaife, J. H. McNeill, and C. Orvig, "Vanadium treatment of type 2 diabetes: a view to the future," Journal of Inorganic Biochemistry, vol. 103, no. 4, pp. 554-558, 2009.

[30] H. Sakurai, Y. Yoshikawa, and H. Yasui, "Current state for the development of metallopharmaceutics and anti-diabetic metal complexes," Chemical Society Reviews, vol. 37, no. 11, pp. 2383-2392, 2008.

[31] B. A. Reul, S. S. Amin, J. P. Buchet, L. N. Ongemba, D. C. Crans, and S. M. Brichard, "Effects of vanadium complexes with organic ligands on glucose metabolism: a comparison study in diabetic rats," British Journal of Pharmacology, vol. 126, no. 2, pp. 467-477, 1999.

[32] P. Buglyo, D. C. Crans, E. M. Nagy et al., "Aqueous chemistry of the vanadium ${ }^{\mathrm{III}}\left(\mathrm{V}^{\mathrm{III}}\right)$ and the $\mathrm{V}^{\mathrm{III}}$-dipicolinate systems and a comparison of the effect of three oxidation states of vanadium compounds on diabetic hyperglycemia in rats," Inorganic Chemistry, vol. 44, no. 15, pp. 5416-542, 2005.

[33] J. Y. Guo, C. C. Han, and Y. M. Liu, "A contemporary treatment approach to both diabetes and depression by cordyceps sinensis: rich in vanadium," Evidence-Based Complementary and Alternative Medicine, vol. 7, no. 3, pp. 387-389, 2010. 


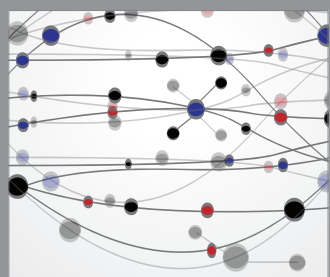

The Scientific World Journal
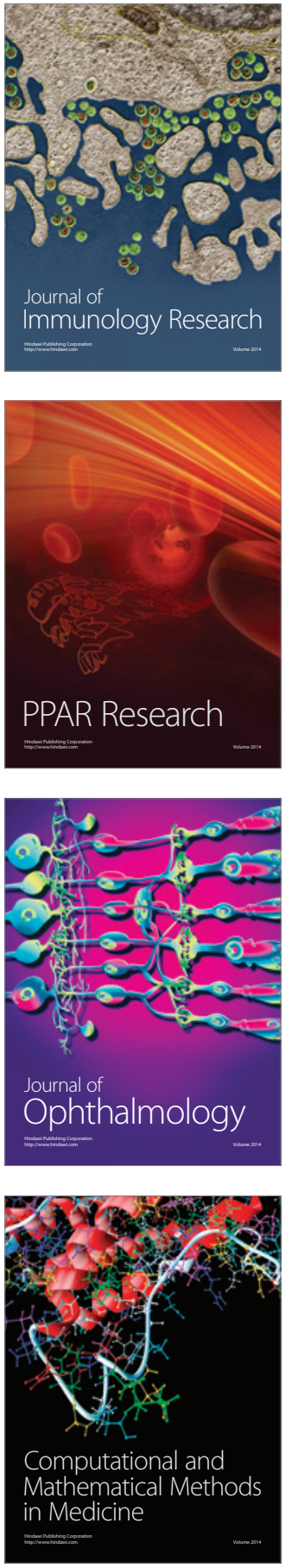

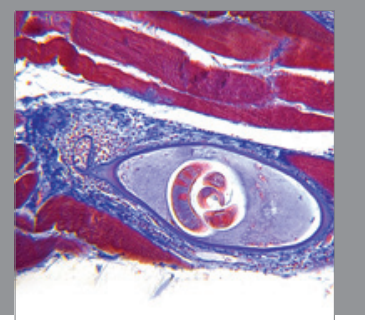

Gastroenterology

Research and Practice
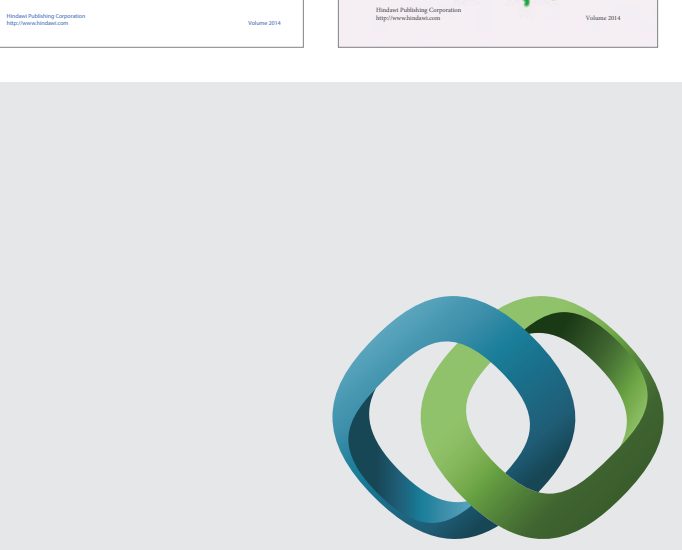

\section{Hindawi}

Submit your manuscripts at

http://www.hindawi.com
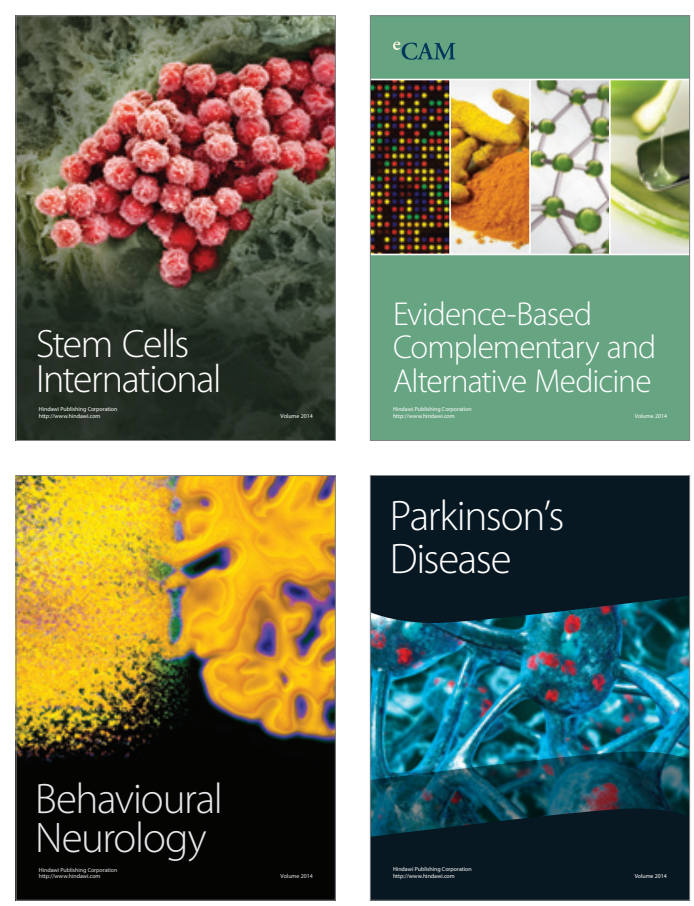

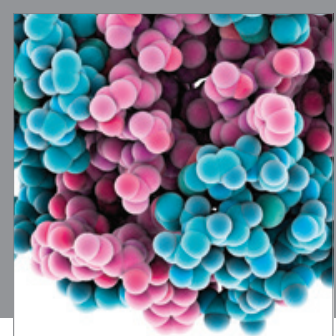

Journal of
Diabetes Research

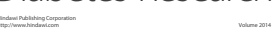

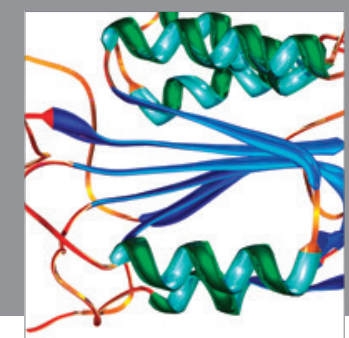

Disease Markers
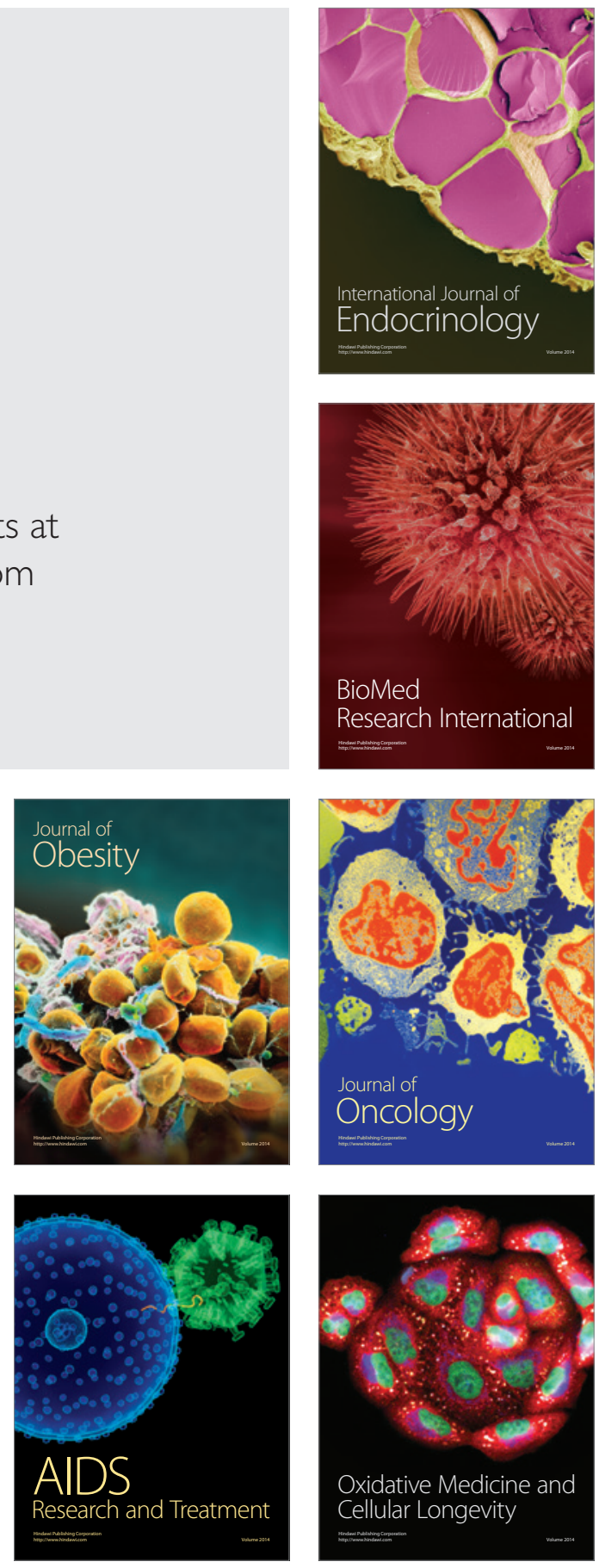